\title{
Activity induced by a progesterone derivative on injury by ischemia-reperfusion in an isolated heart model
}

\author{
Figueroa-Valverde L. ${ }^{1 *}$, Díaz-Cedillo F. ${ }^{2}$, Camacho-Luis A. ${ }^{3}$, García-Cervera E. ${ }^{1}$, Pool-Gómez \\ E. ${ }^{1}$, Rosas-Nexticapa ${ }^{4}{ }^{4}$, López-Ramos M. ${ }^{1}$, Sarao-Alvárez A. ${ }^{1}$ \\ ${ }^{1}$ Laboratory of Pharmacochemistry of Faculty from Chemical-Biological Sciences, University Autonomic of Campeche. \\ Av. Agustín Melgar, Col Buenavista C.P. 24039, Campeche Cam., México. \\ ${ }^{2}$ Escuela Nacional de Ciencias Biológicas del Instituto Politécnico Nacional. Prol. Carpio y Plan de Ayala s/n Col. Santo \\ Tomas, México, D.F. C.P. 11340. \\ ${ }^{3}$ Facultad de Medicina y Nutrición, Centro Investigación en alimentos y nutrición. Universidad Juárez del Estado de \\ Durango. Av. Universidad s/n esq. Fanny Anitua, Zona centro. Durango, México. \\ ${ }^{4}$ Facultad de Nutrición, Universidad Veracruzana. Médicos y Odontólogos s/n, 91010, Xalapa, Veracruz. México.
}

Accepted 20 May, 2013

\begin{abstract}
Several studies indicate that some steroid derivatives have activity at cardiovascular level; nevertheless, there is scarce information about the effects of progesterone and its derivatives on cardiac injury ischemia/reperfusion (I/R). Therefore, in this study, a progesterone derivative was evaluated with the objective of evaluating its activity on $I / R$ in an ischemia-reperfusion model. In addition, molecular mechanism involved in the activity of effect induced by progesterone derivative on perfusion pressure and coronary resistance was assed using the Langendorff technique by measuring left ventricular pressure in the absence or presence of mifepristone, yohimbine, ICl 118,551, atropine, methoctramine and L-NG-nittroarginine methyl esther (L-NAME). The results showed that progesterone derivative reduced infarct size compared with progesterone and control. In addition, it was also observed that the progesterone derivative significantly decreased the perfusion pressure and coronary resistance in isolated heart. Additionally, another set of data indicate that progesterone derivative produces low left ventricular pressure in a dose-dependent manner [0.001 to $100 \mathrm{nM}]$; however, this phenomenon was significantly inhibited by methoctramine (1 $\mathrm{nM})$ and L-NAME (1 $\mathrm{nM})$. In conclusion, these data suggest that a cardioprotective effect of progesterone derivative is through the interaction with $\mathrm{M}_{2}$ muscarinic and activation of nitric oxide synthase which may be responsible for the reduction in myocardial necrosis after ischemia and reperfusion.
\end{abstract}

Key words. Progesterone derivative, ischemia/reperfusion, methoctramine and L-NG-nittroarginine methyl esther (L-NAME).

\section{INTRODUCTION}

There are data both clinical and epidemiological which indicate that myocardial infarction is the main cause of death worldwide (Yusuf et al., 2005; Thygesen et al., 2007; Yeh et al., 2011). Myocardial infarction can be induced by prolonged ischemia which as consequently affects cell viability and ultimately cardiac function. In addition, acute myocardial infarction can produce alterations in the topography of both the infarcted and noninfarcted regions of the ventricle (Pfeffer and Braunwald, 1990; Pfeffer, 1995). There are some reports which indicate that the most effective method of limiting necrosis is restoration of blood flow; however, the effects 
of reperfusion itself may also be associated with tissue injury (Braunwald and Kloner, 1985; Kloner et al., 1989). In addition, some studies suggest that there are differences between both men and women in the myocardial response to ischemia/reperfusion injury (Wang, 2005). These differences may be attributable to the effects of the sex hormones (Miejing et al., 2005; Delyani et al., 1996). In this sense, there are studies which show that $17 \beta$-estradiol, but not 17a-estradiol, reduces myocardial necrosis in rabbits after ischemia and reperfusion (Hale et al., 1996). Other studies suggest that $17 \beta$-Estradiol prevents dysfunction of canine coronary endothelium and myocardium and reperfusion arrhythmias after brief ischemia/reperfusion (Kim et al., 1996). In addition, progesterone has been used in conjunction with estrogen in an ischemia/reperfusion model, resulting in a significantly decreased myocardial injury. The protective effect could be mediated by attenuation of inflammation and its possible interaction with endogenous estrogen (Dhote and Balaraman, 2007). Other studies showed that a progestin (norethindrone acetate) can also reduce ischemia-reperfusion injury in ovariectomized monkeys receiving estrogen therapy previously (Suparto et al., 2005). Nevertheless, there are reports which indicate that the administration of other progesterone derivative (medroxyprogesterone acetate) can inhibit the effects of estradiol that lead to protection of the myocardium from reperfusion injury and that this involves both neutrophil-dependent and neutrophilindependent mechanisms (Jeanes et al., 2006). Apart from the above experiments, which also do not show clearly the cellular site and actual molecular mechanisms of progesterone and its derivatives, data are needed for characterizing the activity induced by this steroid on ischemia-reperfusion injury. To test this aspect, the present study was designed to investigate the effects induced by a progesterone derivative in a myocardial infarction/reperfusion model. In addition, it was thought desirable to evaluate the molecular mechanism involved in the activity of the progesterone derivative on left ventricular pressure, using some pharmacological tools for blocking various biological systems such as mifepristone [progesterone receptor antagonist] (McDonnell and Goldman, 1994), yohimbine $\left[\alpha_{2}\right.$ adrenoreceptor antagonist] (Bruck et al., 2001), ICl 118,551 [selective $\beta_{2}$ receptor blocker] (Bilski et al., 1983), atropine [non-selective muscarinic receptor antagonist] (Tee-Ping et al., 1972), methoctramine [antagonist of the $\mathrm{M}_{2}$ receptor] (Watson et al., 1992), LNG-nittroarginine methyl esther (L-NAME) [a selective inhibitor of nitric oxide synthase] (Moree et al., 1993).

\section{MATERIALS AND METHODS}

The compounds evaluated in this study were purchased from Sigma-Aldrich Co., Ltd. The melting points for the different compounds were determined on an Electrothermal (900 model).
Infrared spectra (IR) were recorded using $\mathrm{KBr}$ pellets on a Perkin Elmer Lambda 40 spectrometer. ${ }^{1} \mathrm{H}$ and ${ }^{13} \mathrm{C}$ NMR spectra were recorded on a Varian VXR-300/5 FT NMR spectrometer at 300 and $75.4 \mathrm{MHz}$ in $\mathrm{CDCl}_{3}$ using TMS as internal standard. Electron Impact Ionization Mass Spectrometry (EIMS) spectra were obtained with a Finnigan Trace GCPolaris Q. spectrometer. Elementary analysis data were acquired from a Perkin Elmer Ser. II CHNS/0 2400 elemental analyzer.

1-(10,13-dimethyl-6,7,8,9,10,11,12,13,14,15,16,17-dodecahydro1H-8-aza-indeno[1,1b]-1 H-cyclopenta[a]phenanthren-17-yl) ethanone (3)

A solution of progesterone (100 $\mathrm{mg}, 0.32 \mathrm{mmol}$ ), phenylhydrazine hydrochloride $(90 \mathrm{mg}, 0.62 \mathrm{mmol})$ in $10 \mathrm{~mL}$ of ethanol was stirred for $10 \mathrm{~min}$ at room temperature. Then $0.5 \mathrm{~mL}$ of hydrochloric acid was added and the mixture was stirred for $48 \mathrm{~h}$ at room temperature. The reaction mixture was evaporated to a smaller volume. After the mixture was diluted with water and extracted with chloroform. The organic phase was evaporated to dryness under reduced pressure, the residue was purified by crystallization from methanol:water $(3: 1)$

\section{Biological evaluation}

All experimental procedures and protocols used in this investigation were reviewed and approved by the animal care and use committee of University Autonomic of Campeche (UAC) and were in accordance with the guide for the care and use of Laboratory Animals (Bayne, 1996). Female rats (Wistar; weighing 200-250 g) were obtained from UAC.

\section{Reagents}

All drugs were dissolved in methanol and different dilutions were obtained using Krebs-Henseleit solution $(\leq 0.01 \%$, v/v).

\section{Experimental design}

Briefly, the female rat $(200-250 \mathrm{~g})$ was anesthetized by injecting them with pentobarbital at a dose rate of $50 \mathrm{mg} / \mathrm{Kg}$ body weight. Then the chest was opened, and a loose ligature passed through the ascending aorta. The heart was then rapidly removed and immersed in ice cold physiologic saline solution. The heart was trimmed of non-cardiac tissue and retrograde perfused via a noncirculating perfusion system at a constant flow rate. It is important to mention that perfusion medium was the Krebs-Henseleit solution $\left(\mathrm{pH} 7.4,37^{\circ} \mathrm{C}\right)$ composed of $(\mathrm{mmol}) ; 117.8 \mathrm{NaCl} ; 6 \mathrm{KCl} ; 1.75$ $\mathrm{CaCl} 2 ; 1.2 \mathrm{NaH}_{2} \mathrm{PO}_{4} ; 1.2 \mathrm{MgSO}_{4} ; 24.2 \mathrm{NaHCO}_{3} ; 5$ glucose and 5 sodium pyruvate. The solution was actively bubbled with a mixture of $\mathrm{O}_{2} / \mathrm{CO}_{2}$ (95:5). The coronary flow was adjusted with a variable speed peristaltic pump. An initial perfusion rate of $15 \mathrm{ml} / \mathrm{min}$ for 5 min was followed by a 15 min equilibration period at a perfusion rate of $10 \mathrm{ml} / \mathrm{min}$. All experimental measurements were done after this equilibration period.

\section{Perfusion pressure}

Evaluation of measurements of perfusion pressure changes induced by drugs administration in this study were assessed using a pressure transducer connected to the chamber where the hearts 
were mounted and the results entered into a computerized data capture system (Biopac).

\section{Inotropic activity}

Contractile function was assessed by measuring left ventricular developed pressure (LVdP), using a saline-filled latex balloon $(0.01$ $\mathrm{mm}$, diameter) inserted into the left ventricle via the left atrium. It is important to mention that latex balloon was bound to cannula which was linked to pressure transducer that was connected with the MP100 data acquisition system.

\section{First stage}

\section{Ischemia/reperfusion model}

After of 15 min equilibration time, the hearts were subjected to ischemia for $30 \mathrm{~min}$ by turning off the perfusion system (Booth et al., 2005). After this period, the system was restarted and the hearts were reperfused for $30 \mathrm{~min}$ with Krebs-Henseleit solution. It is important to mention that hearts were randomly divided into 2 major treatment groups with $n=9$ :

Group I. Hearts were subjected to ischemia/reperfusion but received vehicle only (Krebs-Henseleit solution).

Group II. Hearts were subjected to ischemia/reperfusion and treated with progesterone derivative $(0.001 \mathrm{nM})$ before ischemia period (for $10 \mathrm{~min}$ ) and during the entire period of reperfusion.

It is important to mention that at the end of each experiment, the perfusion pump was stopped, and $0.5 \mathrm{ml}$ of fluorescein solution $(0.10 \%)$ was injected slowly through a sidearm port connected to the aortic cannula. The dye was passed through the heart for $10 \mathrm{~s}$ to ensure its uniform tissue distribution. The presence of fluorescein was used to demarcate the tissue that was not subjected to regional ischemia, as opposed to the risk region. The heart was removed from the perfusion apparatus and cut into two transverse sections at right angles to the vertical axis. The right ventricle, apex, and atrial tissue were discarded. The areas of the normal left ventricle non risk region, area at risk, and infarct region were determined using the technique reported by Boot et al. (2005). Total area at risk is expressed as the percentage of the left ventricle.

\section{Second stage}

\section{Effect induced by progesterone and progesterone derivative} on perfusion pressure

Changes in perfusion pressure as a consequence of increases in time (3-18 $\mathrm{min})$ in the absence (control) or presence of progesterone and its derivative at a concentration of $0.001 \mathrm{nM}$ were determined. The effects were obtained in isolated hearts perfused at a constant-flow rate of $10 \mathrm{ml} / \mathrm{min}$.

\section{Evaluation of effects exerted by progesterone and progesterone derivative on coronary resistance}

The coronary resistance in the absence (control) or presence of progesterone and its derivative at a concentration of $0.001 \mathrm{nM}$ was evaluated. The effects were obtained in isolated hearts perfused at a constant flow rate of $10 \mathrm{ml} / \mathrm{min}$. Since a constant flow was used, changes in coronary pressure reflect the changes in coronary resistance.

\section{Third stage}

Effects induced by the progesterone derivative on left ventricular pressure through progestagen receptors

Intracoronary boluses $(50 \mu \mathrm{l})$ of the progesterone derivative $(0.001$ to $100 \mathrm{nM}$ ) were administered and the corresponding effect on the left ventricular pressure was determined. The dose-response curve (control) was repeated in the presence of mifeprestone at a concentration of $1 \mathrm{nM}$ (duration of preincubation with mifeprestone was by a 10 min equilibration period).

Effect exerted by the progesterone derivative on left ventricular pressure in the presence of $\alpha_{2}$ adrenergic blocker

The boluses $(50 \mu \mathrm{l})$ of the progesterone derivative [0.001 to 100 $\mathrm{nM}$ ] were administered and the corresponding effect on the left ventricular pressure was evaluated. It is important to mention that the bolus injection administered was done in the point of cannulation. The dose-response curve (control) was repeated in the presence of yohimbine at a concentration of $1 \mathrm{nM}$ (duration of preincubation with yohimbine was by a 10 min equilibration period).

Effects induced by the progesterone derivative on left ventricular pressure in the presence of $\beta_{2}$ adrenergic blocker

The boluses $(50 \mu \mathrm{l})$ of progesterone derivative [0.001 to $100 \mathrm{nM}$ ] were administered and the corresponding effect on the left ventricular pressure was evaluated. The dose-response curve (control) was repeated in the presence of $\mathrm{ICl} 118,551$ at concentration of $1 \mathrm{nM}$ (duration of preincubation with ICl 118,551 was by a 10 min equilibration period).

Effects of progesterone derivative on left ventricular pressure in the presence of non-selective muscarinic receptor antagonist

The boluses $(50 \mu \mathrm{l})$ of progesterone derivative [0.001 to $100 \mathrm{nM}]$ were administered and the corresponding effect on the left ventricular pressure was evaluated. The dose-response curve (control) was repeated in the presence of atropine at a concentration of $1 \mathrm{nM}$ (duration of preincubation with methoctramine was by a 10 min equilibration period).

Effects of progesterone derivative on left ventricular pressure in the presence of $M_{2}$ receptor antagonist

The boluses $(50 \mu \mathrm{l})$ of progesterone derivative [0.001 to $100 \mathrm{nM}$ ] were administered and the corresponding effect on the left ventricular pressure was evaluated. The dose-response curve (control) was repeated in the presence of methoctramine at a concentration of $1 \mathrm{nM}$ (duration of pre-incubation with methoctramine was by a 10 min equilibration period).

Effects of progesterone derivative on left ventricular pressure in the presence of L-NAME

The boluses $(50 \mu \mathrm{l})$ of progesterone derivative [0.001 to $100 \mathrm{nM}]$ were administered and the corresponding effect on the left ventricular pressure was evaluated. The dose-response curve (control) was repeated in the presence of L-NAME at concentration of $1 \mathrm{nM} \mathrm{mmol}$ (duration of preincubation with L-NAME was by a 10 min equilibration period). 
Table 1. ${ }^{1} \mathrm{H}$ NMR $\left(300 \mathrm{MHz}, \mathrm{CDCl}_{3}\right)$ data for the progesterone derivative.

\begin{tabular}{cc}
\hline Progesterone derivative & $\left.{ }^{1} \mathbf{H ~ N M R ~ ( 3 0 0 ~} \mathbf{M H z}, \mathbf{C D C l}_{3}\right)$ data (ppm) \\
\hline 0.67 & $\mathrm{~s}, 3 \mathrm{H}$ \\
$0.90-0.95$ & $\mathrm{~m}, 2 \mathrm{H}$ \\
0.98 & $\mathrm{~s}, 3 \mathrm{H}$ \\
$1.12-1.60$ & $\mathrm{~m}, 6 \mathrm{H}$ \\
1.64 & $\mathrm{~m}, 1 \mathrm{H}$ \\
$1.66-1.72$ & $\mathrm{~m}, 3 \mathrm{H}$ \\
1.80 & $\mathrm{~m}, 1 \mathrm{H}$ \\
2.02 & $\mathrm{~m}, 1 \mathrm{H}$ \\
2.16 & $\mathrm{~s}, 3 \mathrm{H}$ \\
$2.19-2.50$ & $\mathrm{~m}, 6 \mathrm{H}$ \\
$3.82-5.72$ & $\mathrm{~m}, 2 \mathrm{H}$ \\
6.22 & $\mathrm{~m}, 1 \mathrm{H}$ \\
$6.38-6.90$ & $\mathrm{~d}, 2 \mathrm{H}, \mathrm{J}=9.66 \mathrm{~Hz}$ \\
11.02 & $\mathrm{~s}, 1 \mathrm{H}$ \\
\hline
\end{tabular}

\section{Statistical analysis}

The obtained values are expressed as average \pm SE, using each heart $(n=9)$ as its own control. The data obtained were put under Analysis of Variance (ANOVA) using the Bonferroni correction factor (Hocht et al., 1999). The differences were considered significant when $p$ was equal or smaller than 0.05 .

\section{RESULTS}

\section{Chemical synthesis}

The yielding of progesterone derivative was of $60 \%$ with melting point of $168-170^{\circ} \mathrm{C}$. In addition, the spectroscopic analyses show signals for IR (Vmax, cm-1) at 3440, and 1720. In addition, the chemical shifts of the spectroscopic analyses of $1 \mathrm{H}$ NMR (Table 1) and 13C NMR for the progesterone derivative is shown in the Table 2. Finally, the results of mass spectroscopy (MS) (70 ev) shown; $\mathrm{m} / \mathrm{z} 389.20[\mathrm{M}+12]$. Additionally, the elementary analysis data for the progesterone derivative $(\mathrm{C} 27 \mathrm{H} 35 \mathrm{NO})$ were calculated $(\mathrm{C}, 83.24 ; \mathrm{H}, 9.06 ; \mathrm{N}, 3.60 ; 0,4.11)$ and found (C, 83.20; H, 9.02; N, 3.58). The biochemical steps for the chemical synthesis are shown in the Figure 1.

\section{Biological activity}

\section{First stage}

Effect of progesterone and its derivative on ischemia/ reperfusion: The results showed that progesterone derivative reduced infarct size expressed as a percentage of the area at risk compared with progesterone and vehicle-treated hearts (Figure 2).

\section{Second stage}

In In this study, the activity induced by the progesterone and its derivative on perfusion pressure and coronary resistance in the isolated rats heart were evaluated. The results obtained from changes in perfusion pressure as a consequence of increases in the time ( 3 to $18 \mathrm{~min}$ ) in absence (control) or in presence of progesterone and its derivative (Figure 3), showed that progesterone derivative $[1 \mathrm{nM}]$ significantly decrease the perfusion pressure $(p=0.05)$ in comparison with the control conditions [1 $\mathrm{nM}]$.

Additionally, another result showed that coronary resistance, calculated as the ratio of perfusion pressure at coronary flow assayed $(10 \mathrm{~mL} / \mathrm{min})$ was low in the presence of progesterone derivative than progesterone and the control conditions $(p=0.06)$ at a concentration of $1 \mathrm{nM}$ (Figure 4).

\section{Third stage}

Figure 5 shows that progesterone derivative decrease the left ventricular pressure in a dose dependent manner [0.001 to $100 \mathrm{nM}]$ and this effect was not inhibited in presence of mifepristone at a dose of $1 \mathrm{nM}$. In addition, results showed that activity exerted by progesterone derivative [0.001 to $100 \mathrm{nM}$ ] decrease the left ventricular pressure and this effect was not inhibited in presence of yohimbine or $\mathrm{ICl} 118,551$ (Figures 6 and 7) drugs at a concentration of $1 \mathrm{nM}$. On the other hand, results shown in the Figures 8 and 9 indicate that progesterone derivative induces a decrease in left ventricular pressure in a dose dependent manner [0.001 to $100 \mathrm{nM}$ ] and that this effect was inhibited by atropine $(p=0.06)$ and methoctramine $(p=0.05)$ at a dose of $1 \mathrm{nM}$. Finally, additional results (Figure 10) showed that the effect induced by the progesterone derivative [0.001 to $100 \mathrm{nM}]$ on perfusion pressure in the presence of L-NAME $(1 \mathrm{nM})$ was inhibited $(p=0.05)$. 
Table 2. ${ }^{13} \mathrm{C}$ NMR $\left(75.4 \mathrm{MHz}, \mathrm{CDCl}_{3}\right)$ data for the progesterone derivative.

\begin{tabular}{cc}
\hline Progesterone derivative & ${ }^{13} \mathbf{C ~ N M R ~}\left(\mathbf{7 5 . 4} \mathbf{~ M H z}, \mathbf{C D C l}_{3}\right)$ data $(\mathbf{p p m})$ \\
\hline 13.2 & $\mathrm{C}-26$ \\
17.80 & $\mathrm{C}-25$ \\
20.08 & $\mathrm{C}-11$ \\
23.70 & $\mathrm{C}-22$ \\
27.08 & $\mathrm{C}-23$ \\
27.70 & $\mathrm{C}-16$ \\
29.22 & $\mathrm{C}-29$ \\
30.83 & $\mathrm{C}-5$ \\
31.41 & $\mathrm{C}-21$ \\
32.08 & $\mathrm{C}-20$ \\
33.90 & $\mathrm{C}-7$ \\
34.60 & $\mathrm{C}-4$ \\
38.27 & $\mathrm{C}-10$ \\
39.13 & $\mathrm{C}-17$ \\
43.80 & $\mathrm{C}-9$ \\
51.77 & $\mathrm{C}-6$ \\
56.08 & $\mathrm{C}-8$ \\
63.40 & $\mathrm{C}-24$ \\
118.06 & $\mathrm{C}-18$ \\
120.47 & $\mathrm{C}-14$ \\
122.04 & $\mathrm{C}-13$ \\
126.13 & $\mathrm{C}-15$ \\
129.70 & $\mathrm{C}-3$ \\
131.52 & $\mathrm{C}-2$ \\
144.84 & $\mathrm{C}-12$ \\
146.50 & $\mathrm{C}-19$ \\
206.14 & $\mathrm{C}-27$ \\
\hline &
\end{tabular}

\section{DISCUSSION}

\section{Biological evaluation}

There are studies which indicate that ischemia/reperfusion ( $I / R)$ injury occurs when a tissue is temporarily deprived of blood supply and the return of the blood supply triggers an intense inflammatory response (Park and Lucchesi, 1999; Arumugam et al., 2004). Analyzing these data, in this study in the first stage, the effect of progesterone derivative was evaluated in an ischemia-reperfusion model. The results showed that progesterone derivative reduced infarct size expressed as a percentage of the area at risk compared with vehicle-treated hearts. This phenomenon can be conditioned by generation of some substances involved in endothelium of coronary artery (Bouis et al., 2001) or by the influence exerted by progesterone derivative on blood pressure which consequently bring reduction in the infarct size, and decrease the myocardial injury after ischemia-reperfusion similar to those reported with steroid derivatives (Beer et al., 2002). In order to evaluate these hypotheses, we evaluated the effect of proges- terone derivative on blood vessel capacity and coronary resistance translated as changes in perfusion pressure in isolated rat heart (Langendorff model). The results show that progesterone derivative significantly decreased the perfusion pressure over time (3-18 min) compared to the control conditions. These data suggest that progesterone derivative exerts effects on perfusion pressure which could subsequently modify vascular tone and coronary resistance. In this sense, the effects of progesterone derivative on coronary resistance were evaluated. We found that coronary resistance was decreased by the progesterone derivative. These data suggest that progesterone derivative exerts effect on vascular tone. To characterize the molecular mechanism of this phenomenon, we analyzed the reports of some investigations which indicate that progesterone induces its effect on blood pressure via activation of the progesterone receptor (Williams and Lefkowitz, 1977; Graham and Clarke, 1997). For this reason, we used mifepristone, a progesterone receptor blocker (Watson et al., 1992) to determine if the effects of progesterone derivative on left ventricular pressure were via the progesterone receptor. It is important to mention that interaction of progesterone 

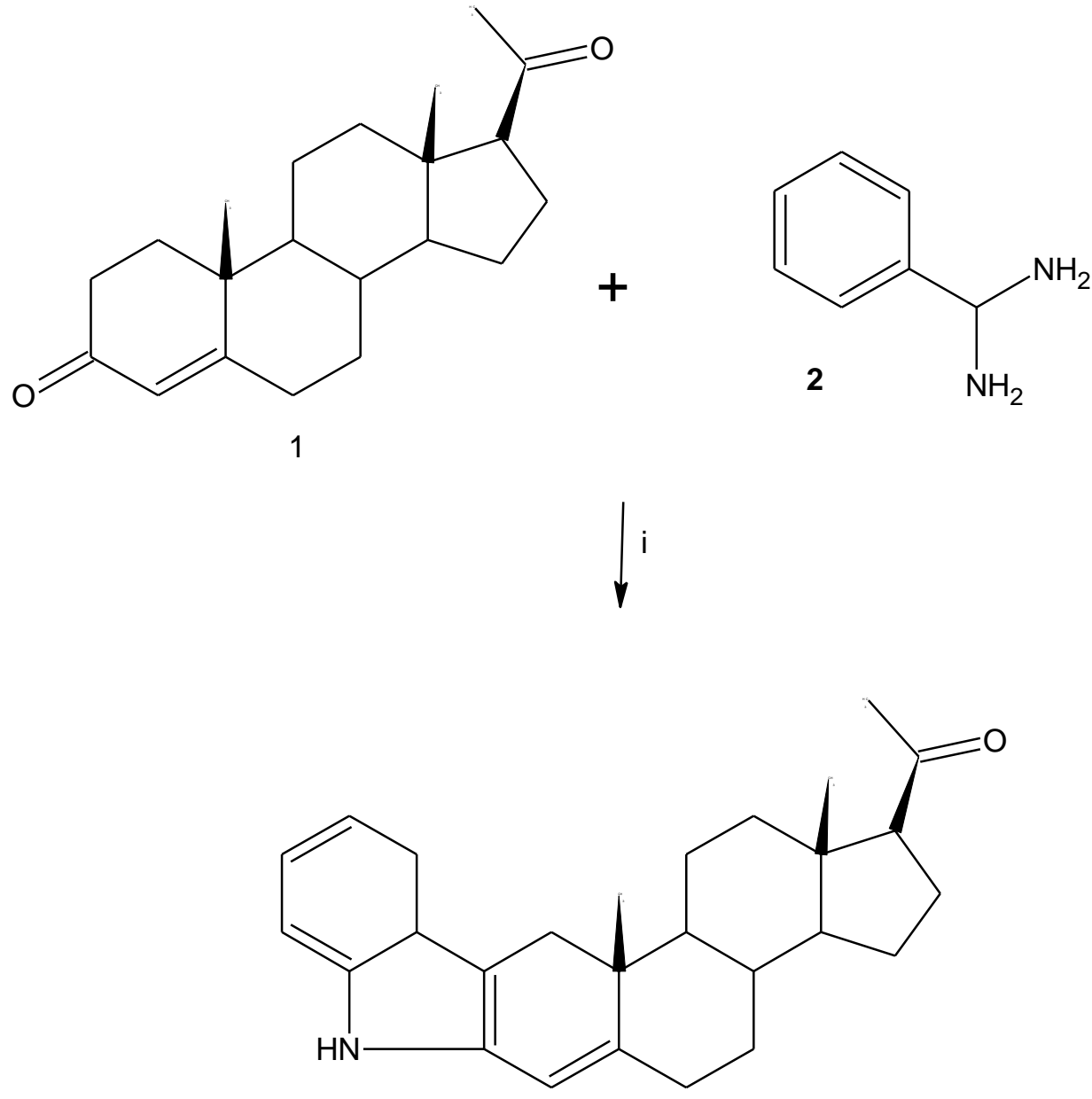

3

Figure 1. Synthesis of 1 -(10,13-dimethyl-6,7,8,9,10,11,12,13,14,15,16,17-dodecahydro- $1 \mathrm{H}$ 8-aza-indeno[1,1b]-1H-cyclopenta[a]phenanthren-17-yl)ethanone (3). Reaction between progesterone (1) and Phenylhydrazine (2) to form 3. $i=$ hydrochloric acid/rt.

derivative with the progesterone-receptor may be a key requirement for the protective effect of this steroid on ischemic injury such as happening with activity exerted by other type of steroids (Hale et al., 1996). Our results showed that the effects of progesterone derivative were not inhibited by mifepristone, suggesting that the molecular mechanism is not via the progesterone receptor.

Analyzing these results and other reports indicate that progesterone can regulate adrenal catecholamine synthesis (Lilley et al., 1976), which has an important role in the development or maintenance of elevated blood pressure. Therefore, in this study the biological activity of progesterone derivative on left ventricular pressure in the absence or presence of yohimbine (Figure 5) or $\mathrm{ICl}$ 118,551 (Figure 6) was evaluated. Our results showed that the effect of progesterone derivative was not inhibited by yohimbine or ICI 118,551 , indicating that the molecular mechanism involved is not through adrenergic activity. Analyzing these results and other reports indicate that other progesterone derivative (progesteronecarbachol) induces activation of $M_{2}$ muscarinic which induces consequently a negative inotropic response and low blood pressure by activation of nitric oxide synthase (Figueroa-Valverde et al., 2012). Therefore, in this study the activity of progesterone derivative on left ventricular pressure was evaluated in the absence or presence of atropine (Figure 7). The results showed that the effect of progesterone-derivative on left ventricular pressure was inhibited in the presence of atropine. These results indicate that the effect of the progesterone derivative is via activation of the muscarinic receptor. Therefore, analyzing these experimental data, we also considered validating the effect of progesterone derivative on left ventricular pressure via the $M_{2}$ receptor. In this sense, in this study we evaluated the effect of progesterone- 


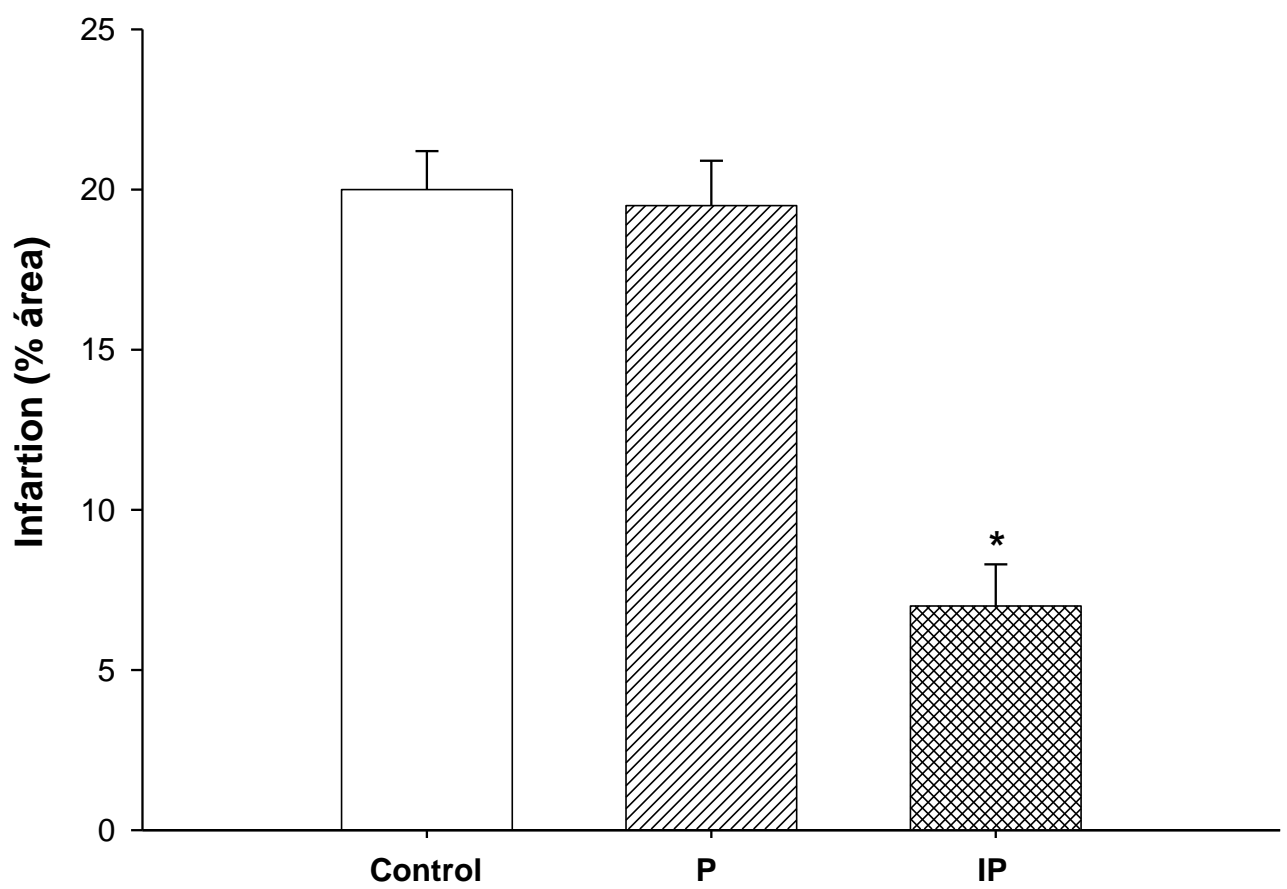

Figure 2. Effect exerted by progesterone and its derivative (IP) on cardiac ischemia/reperfusion. The results showed that IP significantly reduced infarct size $(p=0.05)$ expressed as a percentage of the area at risk compared with progesterone $(P)$ and vehicle-treated hearts. Each bar represents the mean \pm S.E. of 9 experiments.

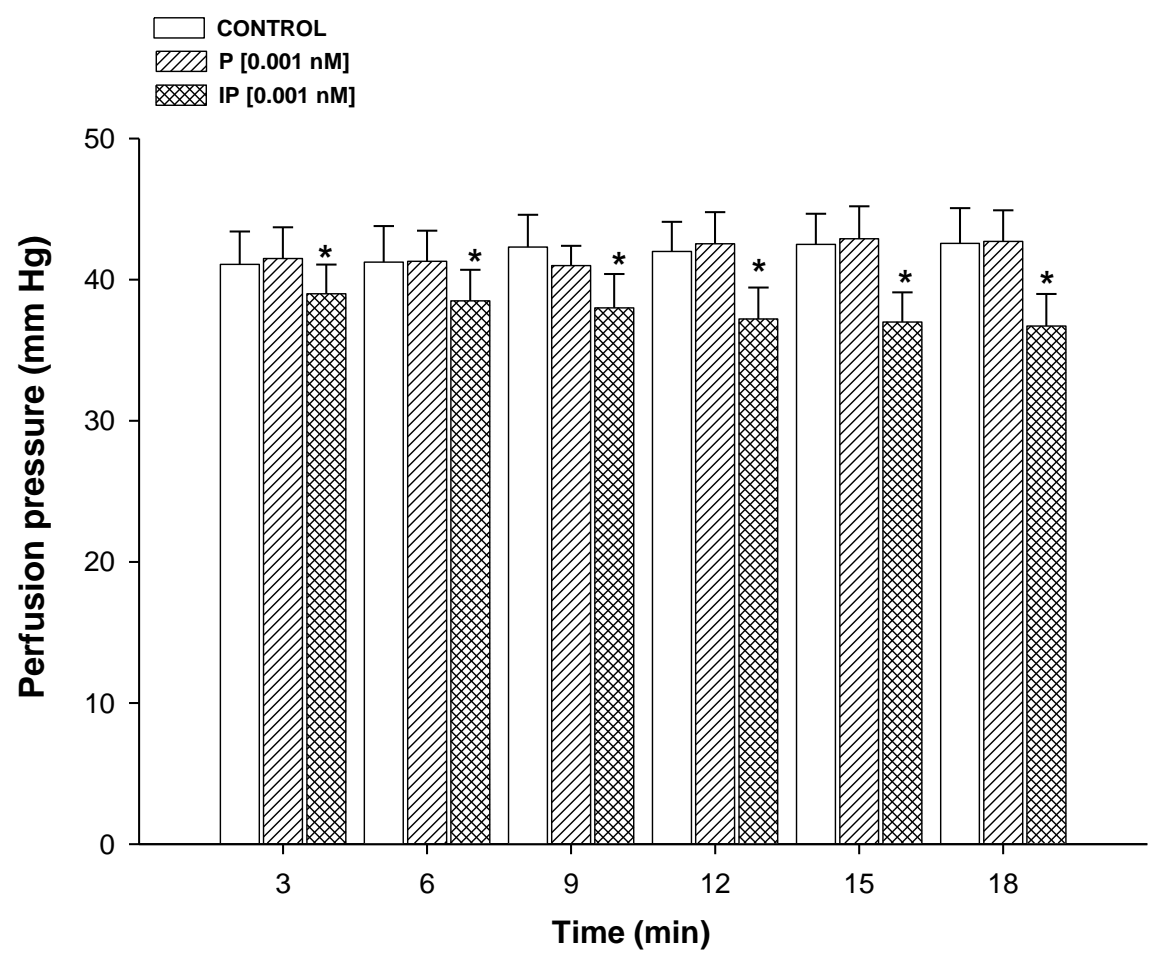

Figure 3. Effect induced by progesterone and progesterone derivative (IP) on perfusion pressure. The results showed that IP significantly decreased the perfusion pressure $(p$ $=0.05)$ through of time (3-18 $\mathrm{min})$ in comparison with progesterone $(P)$ and the control conditions. The effect is expressed as the area under the curve, and each bar represents the mean \pm S.E. of 9 experiments. 


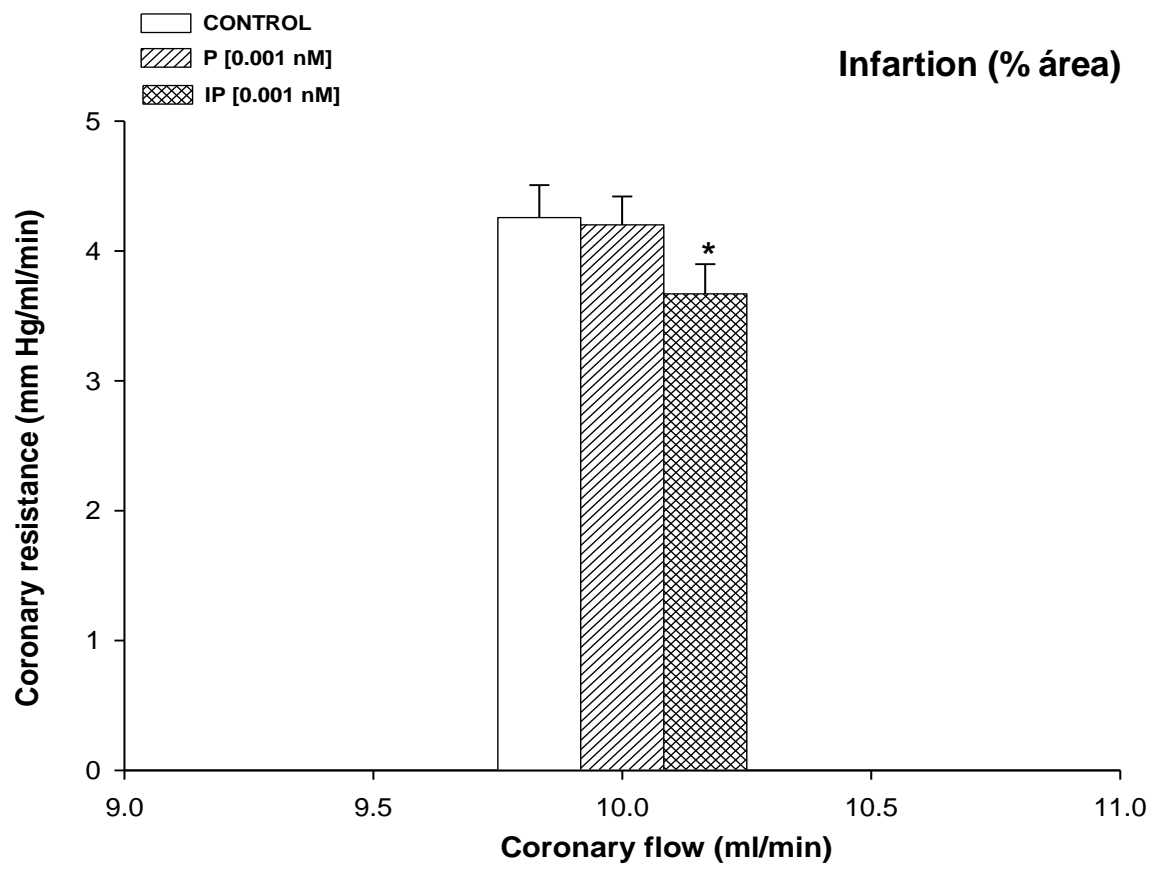

Figure 4. Activity induced by progesterone and progesterone derivative (IP) on coronary resistance. The results showed that coronary resistance was lower in presence of IP $(p=0.06)$ in comparison with progesterone $(\mathrm{P})$ and the control conditions. The effect it is expressed as the area under the curve, and each bar represents the mean \pm S.E. of 9 experiments.

- IP

O IP + MIFEPRESTONE [1 nM]

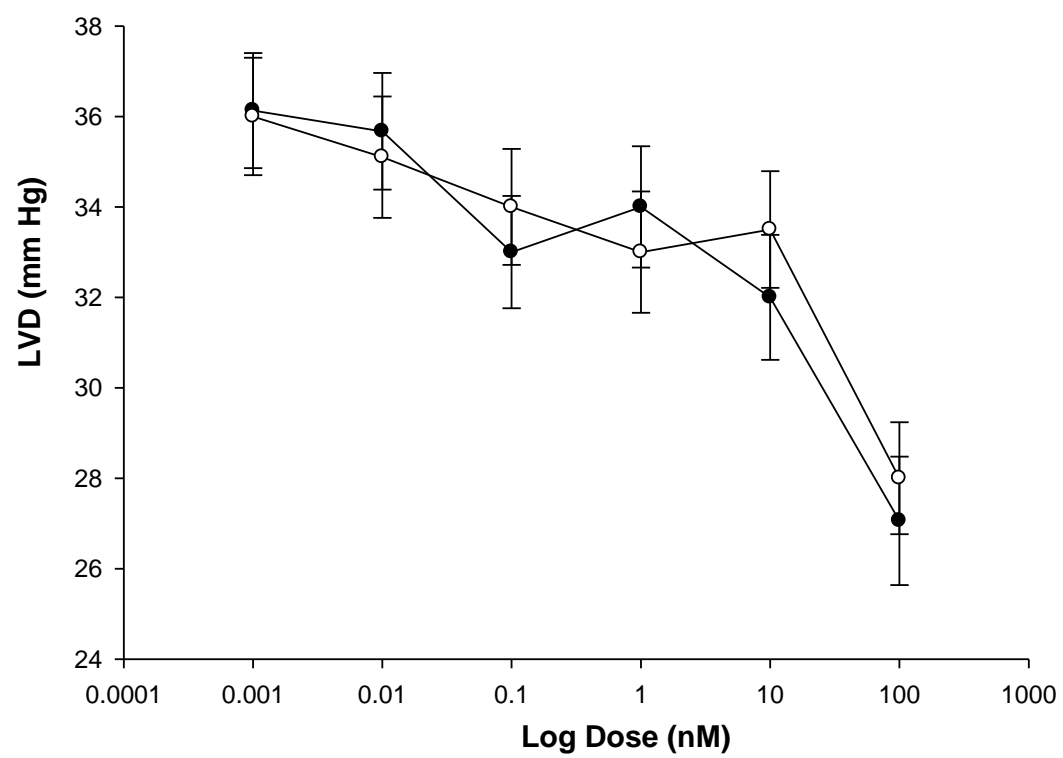

Figure 5. Effects induced by progesterone derivative (IP) on left ventricular pressure through progesterone-receptor. Intracoronary boluses $(50 \mu \mathrm{l})$ of IP (0.001 to $100 \mathrm{nM}$ ) were administered and the corresponding effect on the perfusion pressure was determined. The results showed that IP decreased the perfusion pressure in a dependent dose manner and this effect was not inhibited in presence of mifeprestone $(1 \mathrm{nM})$. The effect it is expressed as the area under the curve, and each bar represents the mean \pm S.E. of 9 experiments. 
- PROGESTERONE-FH

O PROGESTERONE-FH + YOHIMBINE [1 nM]

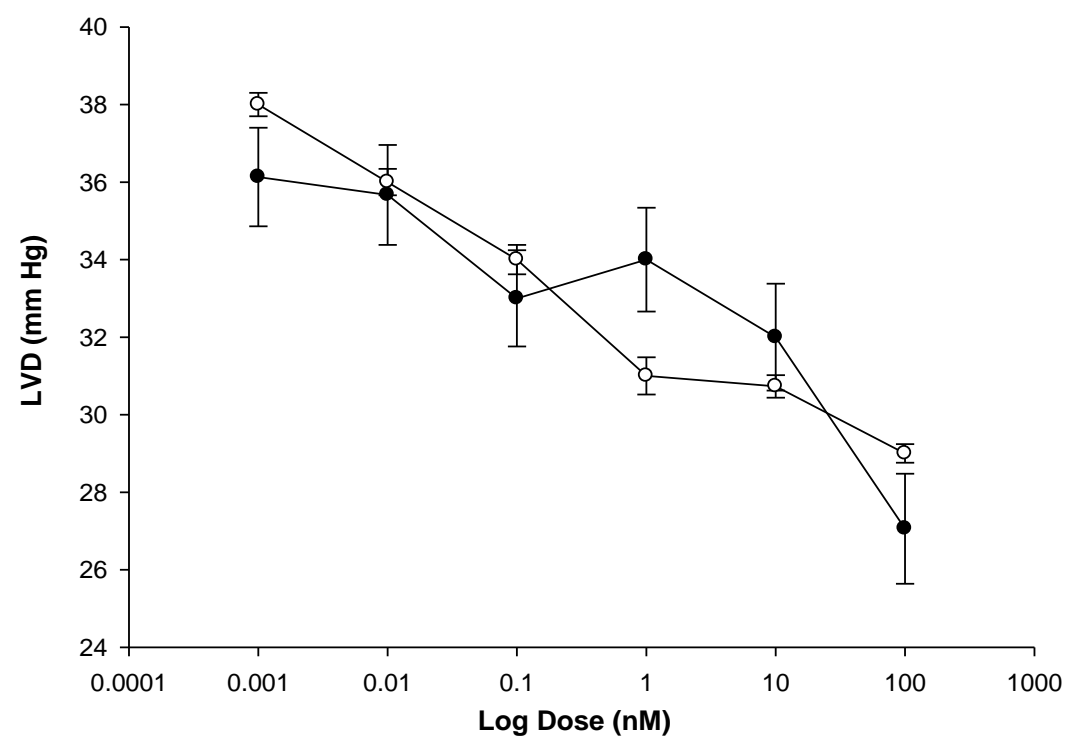

Figure 6. Effect exerted by progesterone derivative (IP) on left ventricular pressure through of $\alpha_{2}$-adrenergic receptor. The progesterone derivative $(0.001$ to $100 \mathrm{nM}$ ) was administered (intracoronary boluses, $50 \mu \mathrm{l}$ ) and the corresponding effect on the left ventricular pressure was evaluated in absence and presence of yohimbine $(1 \mathrm{nM})$. The results showed that activity induced by IP on perfusion pressure was not inhibited in presence of yohimbine. The effect is expressed as the area under the curve, and each bar represents the mean \pm S.E. of 9 experiments.

- PROGESTERONE-FH

P PROGESTERONE-FH + ICI [1 nM]

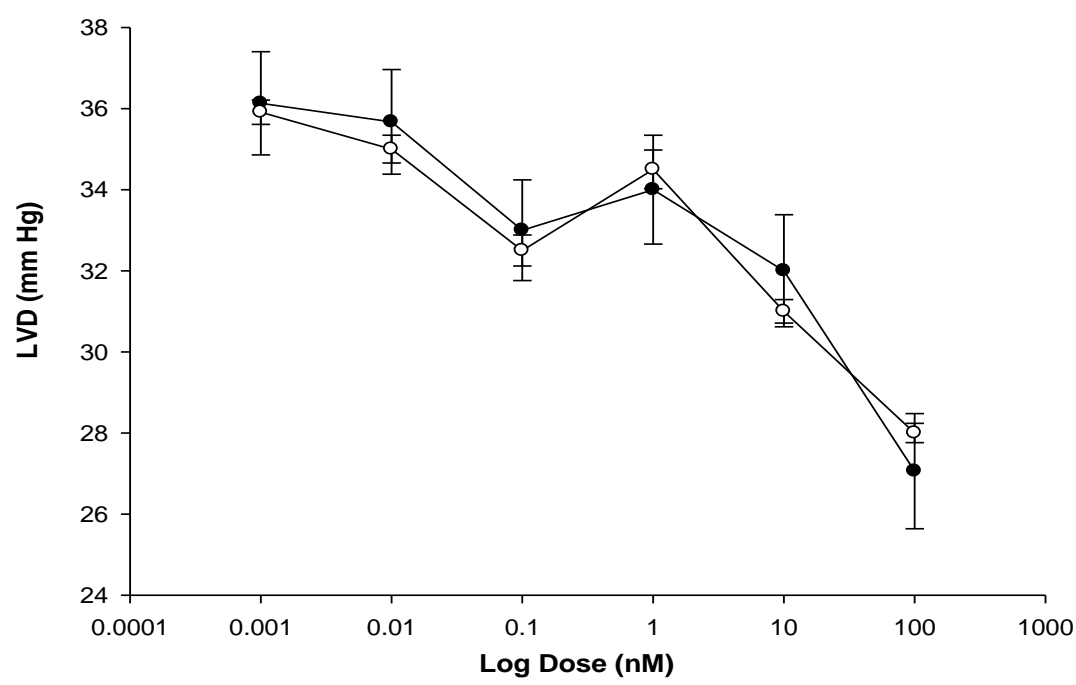

Figure 7. Activity induced by progesterone derivative (IP) on left ventricular pressure through of $\beta_{2}$-adrenergic receptor. Intracoronary boluses $(50 \mu \mathrm{l})$ of IP ( 0.001 to $100 \mathrm{nM})$ were administered and the corresponding effect on the left ventricular pressure was evaluated in absence and presence of ICI 118,551 (1 $\mathrm{nM}$ ). The results showed that activity induced by IP on left ventricular pressure was not inhibited in presence of $\mathrm{ICI} 118,551$. The effects it is expressed as the area under the curve, and each bar represents the mean \pm S.E. of 9 experiments. 


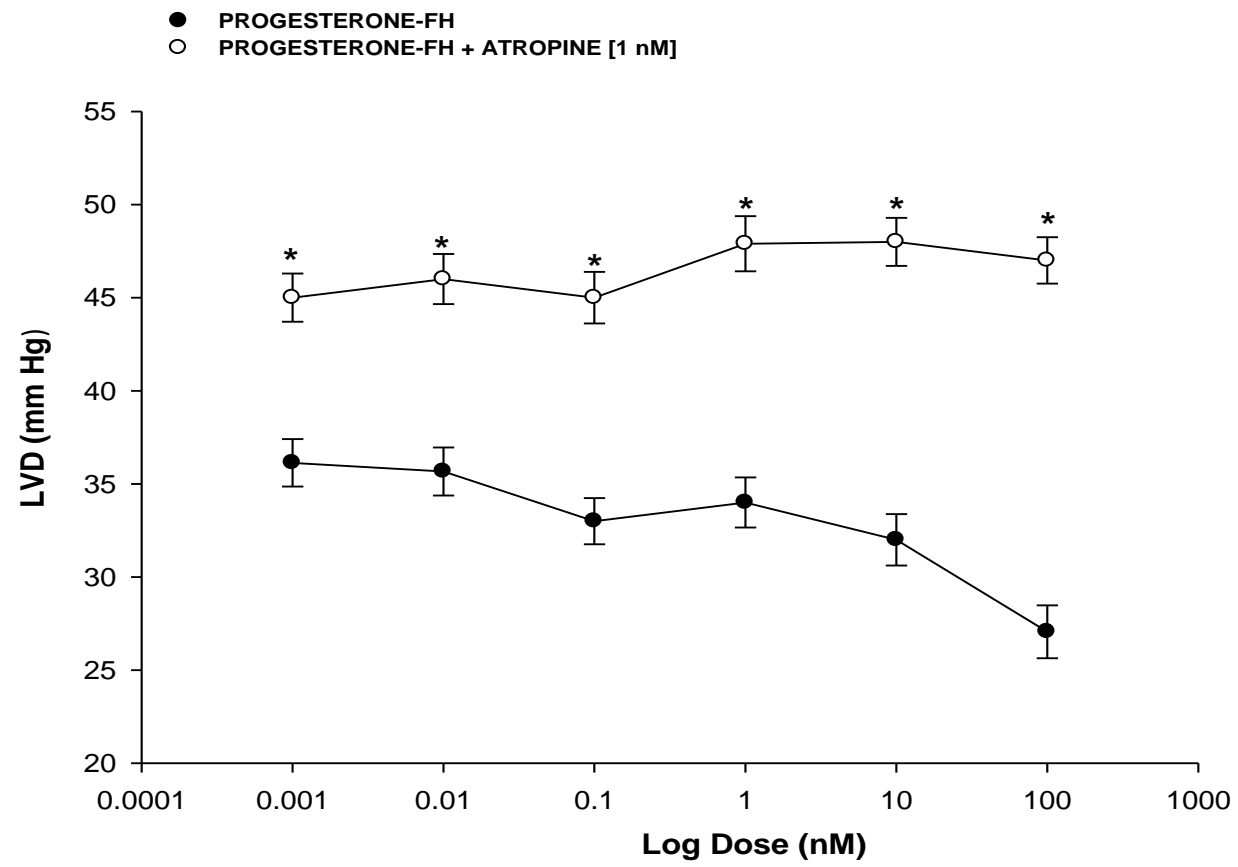

Figure 8. Effects induced by progesterone derivative (IP) on left ventricular pressure through of muscarinic receptors. Intracoronary boluses $(50 \mu \mathrm{l})$ of IP $[0.001$ to $100 \mathrm{nM}]$ were administered in absence and presence of atropine $(1 \mathrm{nM})$. The results showed that effect induced by IP on left ventricular pressure in presence of atropine was significantly inhibited ( $p$ $=0.06$ ). The effect it is expressed as the area under the curve, and each bar represents the mean \pm SE of 9 experiments.

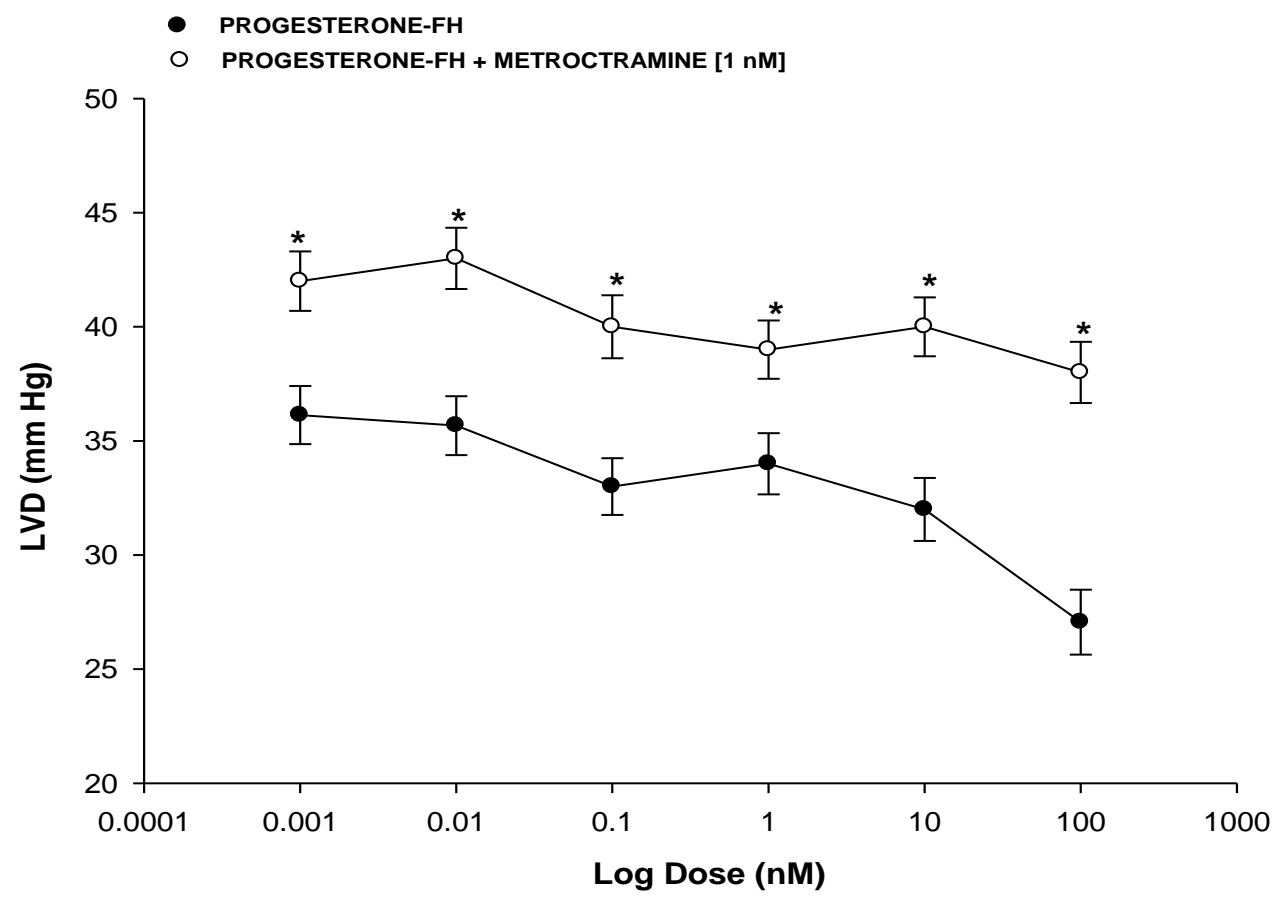

Figure 9. Effects induced by progesterone derivative (IP) on left ventricular pressure through of M2 muscarinic receptor. Intracoronary boluses $(50 \mu \mathrm{l})$ of IP $[0.001$ to $100 \mathrm{nM}]$ were administered in absence and presence of metroctramine $(1 \mathrm{nM})$. The results showed that effect induced by IP on left ventricular pressure in presence of metroctramine was significantly inhibited $(p=0.05)$. The effect it is expressed as the area under the curve, and each bar represents the mean \pm SE of 9 experiments. 
IP

O IP + L-NAME [1 nM]

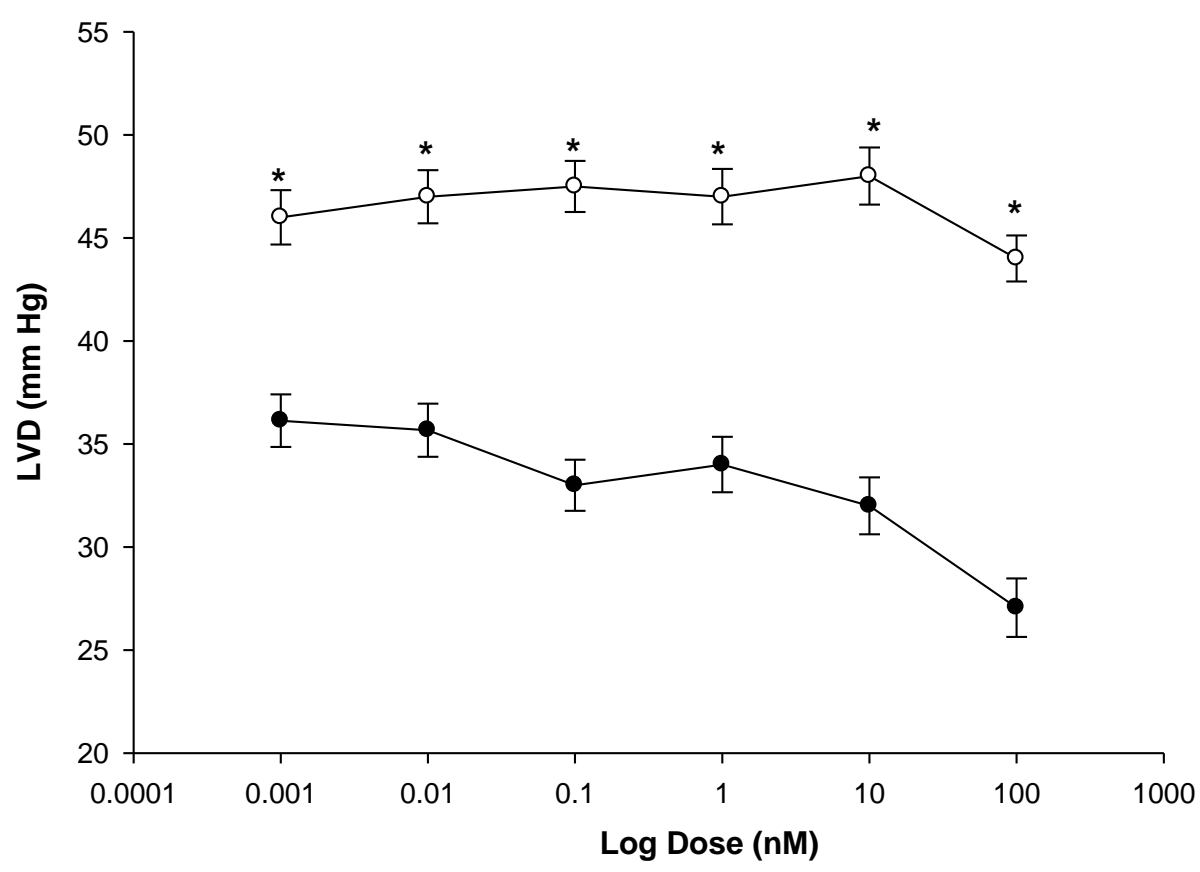

Figure 10. Effects exerted by progesterone derivative (IP) on left ventricular pressure through of synthesis of nitric oxide. The progesterone derivative (0.001 to $100 \mathrm{nM})$ was administered (intracoronary boluses, $50 \mu \mathrm{l}$ ) and the corresponding effect on the perfusion pressure was evaluated in the absence and presence of L-NAME (1 nM). The results showed that activity induced by IP on perfusion pressure in presence of L-NAME was inhibited significantly $(p=0.05)$. The effect it is expressed as the area under the curve, and each bar represents the mean \pm S.E. of 9 experiments.

derivative in the absence or presence of methoctramine. The results showed that the activity of progesterone derivative on left ventricular pressure in the presence of methoctramine was blocked significantly. These results show that the activity of steroid-derivate on left ventricular pressure involved indirect stimulation of the $M_{2}$ receptor. Nevertheless, to evaluate which vasoactive substance could also be involved in the changes induced by progesterone derivative on left ventricular pressure, we also validated the effect of the progesterone derivative on left ventricular pressure via nitric oxide. The effect of progesterone derivative in the absence or presence of $L$ NAME was evaluated. The results show that the effect of progesterone derivative on perfusion pressure was blocked in the presence of L-NAME. These data indicate that activity exerted by progesterone derivative on left ventricular pressure is through activation of nitric oxide synthase and increased production of nitric oxide leading to decrease of ischemia-reperfusion injury as reported with other type of steroids (Gabel et al., 2005).

\section{Abbreviations}

EIMS, Electron Impact Ionization Mass Spectrometry; L-
NAME, L-NG-nittroarginine methyl esther; IR, infrared spectra.

\section{Conclusions}

The experimental data obtained in this study suggest that progesterone derivative exerts its effect on left ventricular pressure via activation of the $\mathrm{M}_{2}$ muscarinic receptor and this phenomenon also involves stimulation of nitric oxide synthase.

\section{REFERENCES}

Arumugam T, Shiels I, Woodruff T, Granger N, Taylor S (2004). The role of the complement system in ischemia-reperfusion injury. SHOCK. 21(5): 401-409.

Bayne K (1996). Revised Guide for the Care and Use of Laboratory Animals available. Am. Physiol. Soc. Physiol. 39(4): 208-211.

Beer S, Reincke M, Kral M, Lie S, Schmidt W, Allolio B, Neubauer S (2002). Susceptibility to Cardiac Ischemia/Reperfusion Injury Is Modulated by Chronic Estrogen Status. J. Cardiov. Pharmacol. 40:420-428.

Bilski AJ, Halliday SE, Fitzgerald JD, Wale JL (1983). The Pharmacology of a [beta]2-Selective Adrenoceptor Antagonist (ICl 118,551). J. Cardiovasc. Pharmacol. 5:430-437.

Booth E, Obeid N, Lucchesi B (2005). Activation of estrogen receptor- $\alpha$ 
protects the in vivo rabbit heart from ischemia-reperfusion injury. Am. J. Physiol. Heart. 289(5):5H2039-H2047.

Bouis D, Hospers G, Meijer C, Molema G, Mulder N (2001). Endothelium in vitro: $A$ review of human vascular endothelial cell lines for blood vessel-related research. Angiogenesis. 4(2):91-102.

Braunwald E, Kloner R (1985). Myocardial reperfusion:a double-edged sword?. J. Clin. Invest. 76(5):1713-1719.

Bruck H, Gössl M, Spitthöver R, Schäfers R, Kohnle M, Philipp T, Wenzel R (2001). The nitric oxide synthase inhibitor L-NMMA potentiates noradrenaline-induced vasocons-triction: effects of the alpha 2 receptor antagonist yohimbine. J. Hypertens. 19;907-911.
Delyani J, Murohara T, Nossuli T, Lefer A (1996). Protection from Myocardial Reperfusion Injury by Acute Administration of $17 \beta$ Estradiol. J. Mol. Cell. Cardiol. 28(5):1001-1008. 